\title{
Analysis and Modeling of Threatening Factors of Workforce's Health in Large-Scale Workplaces: Comparison of Four-Fitting Methods to select optimum technique
}

\author{
Iraj Mohammadfam ${ }^{1}$, Ahmad Soltanzadeh $^{2}$, Abbas Moghimbeigi $^{3}$, Behrouz Alizadeh Savareh $^{4}$
}

${ }^{1}$ Ph.D. of Occupational Hygiene Engineering, Associate Professor, Department of Occupational Hygiene Engineering, School of Public Health and Research Center for Health Sciences, Hamadan University of Medical Sciences, Hamadan, Iran

${ }^{2} \mathrm{Ph}$.D. of Occupational Hygiene Engineering, Department of Occupational Hygiene Engineering, School of Public Health and Research Center for Health Sciences, Hamadan University of Medical Sciences, Hamadan, Iran

${ }^{3}$ Ph.D. of Biostatistics, Associate Professor, Department of Biostatistics and Epidemiology and Modeling of Non communicable Disease Research Canter, School of Public Health, Hamadan University of Medical Sciences,

Hamadan, Iran

${ }^{4}$ Ph.D. Candidate of Medical Informatics, Department of Medical Informatics, Allied Medicine, Shahid Beheshti University of Medical Sciences, Tehran, Iran

\section{Type of article: Original}

\begin{abstract}
Introduction: Workforce is one of the pillars of development in any country. Therefore, the workforce's health is very important, and analyzing its threatening factors is one of the fundamental steps for health planning. This study was the first part of a comprehensive study aimed at comparing the fitting methods to analyze and model the factors threatening health in occupational injuries.

Methods: In this study, 980 human occupational injuries in 10 Iranian large-scale workplaces within 10 years (2005-2014) were analyzed and modeled based on the four fitting methods: linear regression, regression analysis, generalized linear model, and artificial neural networks (ANN) using IBM SPSS Modeler 14.2.

Results: Accident Severity Rate (ASR) of occupational injuries was $557.47 \pm 397.87$. The results showed that the mean of age and work experience of injured workers were $27.82 \pm 5.23$ and $4.39 \pm 3.65$ years, respectively. Analysis of health-threatening factors showed that some factors, including age, quality of provided H\&S training, number of workers, hazard identification (HAZID), and periodic risk assessment, and periodic H\&S training were important factors that affected ASR. In addition, the results of comparison of the four fitting methods showed that the correlation coefficient of ANN $(\mathrm{R}=0.968)$ and the relative error $(\mathrm{R} . \mathrm{E})$ of ANN $(\mathrm{R} . \mathrm{E}=0.063)$ were the highest and lowest, respectively, among other fitting methods.

Conclusion: The findings of the present study indicated that, despite the suitability and effectiveness of all fitting methods in analyzing severity of occupational injuries, ANN is the best fitting method for modeling of the threatening factors of a workforce's health. Furthermore, all fitting methods, especially ANN, should be considered more in analyzing and modeling of occupational injuries and health-threatening factors as well as planning to provide and improve the workforce's health.

Keywords: workforce's health, occupational injury, fitting methods, accident severity rate (ASR), threatening factors
\end{abstract}

\section{Introduction}

Designing, implementing, and monitoring of health programs that provide, maintain, and improve workforce's health can bring more human, social, and economic benefits (1-3). Strategic planning of health requires basic and practical information about health threats and the threatening factors that affect health. One of the main threats in

\section{Corresponding author:}

Ahmad Soltanzadeh, Department of Occupational Hygiene Engineering, School of Public Health and Research Center for Health Sciences, Hamadan University of Medical Sciences, Hamadan, Iran.

Tel: +98.9120187486, Email: soltanzadeh.ahmad@gmail.com

Received: September 02, 2015, Accepted: October 13, 2015, Published: February 2016

iThenticate screening: September 26, 2015, English editing: October 23, 2015, Quality control: January 03, 2016

(C) 2016 The Authors. This is an open access article under the terms of the Creative Commons Attribution-NonCommercialNoDerivs License, which permits use and distribution in any medium, provided the original work is properly cited, the use is non-commercial and no modifications or adaptations are made. 
large-scale workplaces is occupational injuries (3-4). The World Health Organization (WHO) knows occupational injuries as an epidemic phenomena in the field of public health (5-6). Also, the International Labor Organization (ILO) reported that approximately 268 million occupational accidents leading to injuries occur in the different workplaces, with over 2.2 million of them per year resulting in death $(5,7)$. The design and development of preventive and control measures in the field of health and safety in workplaces requires appropriate and practical data and information. So, as much as the findings of occupational injuries analysis become more acceptable, they can be used as a basis for planning and management of health issues in workplaces. Using the results of the studies, we may be able to determine the important and affecting factors on injuries as well as better management and control of occupational accidents and severity of injuries (8-10). One of the main threats arising from occupational accidents is severity of damages and injuries. Accident severity rate (ASR) is one of the important indices for analysis and modeling of the severity of occupational injuries $(11,12)$ Therefore, analysis of this index using modeling techniques can provide accurate identification of health threatening factors, as well as help managers and engineers to design and develop various health programs to prevent and reduce such injuries $(8,13)$. Analysis and modeling of health problems using fitting methods and statistical modeling techniques, such as linear regression, generalized linear model, regression analysis, and artificial neural networks (ANN), can lead to a better understanding and identification of the health-threatening factors in a workforce $(8,14,15)$. In spite of some studies in this field, a comprehensive study on occupational injuries' severity comparing multiple regression methods to analyze and model health threatening factors in large-scale workplaces has not been observed. Therefore, this study was designed and implemented with the purpose of comparing the four fitting methods to be used in causal analysis and modeling of the factors that affect the severity of injuries as a threat to the workforces' health and in order to select the optimum technique in ASR modeling.

\section{Material and Methods}

This analytical and cross-sectional study was implemented in Iranian large-scale workplaces, including 10 power plant construction worksites. Selection of construction sites for this study was due to the fact that the rate of severe accidents and sometimes fatal accidents in construction is higher than that observed in other workplaces $(16,17)$. In the present study, 980 occupational injuries within 10 years (2005-2014) were analyzed and modeled.

\subsection{Study implementation}

This study was carried out in four stages as follows:

2.1.1. First Stage: Occupational injuries description

Description of occupational injuries was done according to accident investigation forms, interviews with injured workforce, witnesses, supervisors, managers, and other personnel. All registered documents of occupational injuries that were collected over a period of 10 years (2005-2014) were peer assessed and reviewed. Occupational injuries with incomplete data were excluded from the study. Finally, a total of 980 accidents that resulted in injuries to the workforce were selected for the study. Accident severity rate (ASR) as a health threat to workforces was analyzed in this study. ASR is an index for quantitative analysis and modeling of occupational injuries. ASR was applied to measuring health performance of large workplaces and identifying problems (12). According to the Occupational Safety and Health Administration (OSHA), ASR was calculated as follows (18): ASR = (total number of lost work days due to accidents and injures $\times 200000 /$ total number of worked hours of workforces).

2.1.2. Second stage: Data collection of IF, OF, TF \& RMF

Data of individual and organization factors (IF \& OF) in addition to documents of health and safety (H\&S) training system (TF) and H\&S risk management (RMF), which were established and implemented in the studied large-scale workplaces, were collected by using designed checklists and results of data collection in the occupational injuries description stage. Individual factors (IF) included average age, work experience, educational level, and marital status. Organization factors (OF) or characteristics of the workplace management and structure included job title, activity types during occupational injuries, the number of workers, existing time pressure, and types of employment (formal or contractor). H\&S Training Factors (TF) included pre-employment training, periodical training, past injury training, personal protective equipment (PPE) training, housekeeping training, and quantity and quality of training. $\mathrm{H} \& \mathrm{~S}$ risk management factors (RMF) were hazard identification (HAZID), periodic risk assessment, accident investigation, risk control measures such as PPE, implementing tool box meeting (TBM) and housekeeping, applying H\&S checklists, establishment of incident report, and H\&S audit.

2.1.3. Third Stage: Analyzing and modeling of ASR by four fitting methods

Analysis and modeling of ASR were performed using the four fitting methods including linear regression, regression analysis, generalized linear model, and artificial neural networks (ANN) by IBM SPSS Modeler 14.2. Linear regression is a common statistical technique for classifying records based on the values of numeric input fields. 
Linear regression fits a straight line or surface that minimizes the discrepancies between predicted and actual output values (19). Regression analysis is a statistical tool for the investigation of relationships between factors. Usually, the investigator seeks to ascertain the causal effect of one factor on another. The investigator also typically assesses the "statistical significance" of the estimated relationships, that is, the degree of confidence that the true relationship is close to the estimated value $(14,20)$. Dissimilar to the general linear model, in the generalized linear model, the dependent variable is related linearly to the factors using a specified link function. Moreover, the model allows the dependent factors to have an abnormal distribution (21). Finally, artificial neural network (ANN) is a simplified model that shows the way the human brain processes information. It works by simulating a large number of interconnected processing units that resemble abstract versions of neurons $(20,22)$.

2.1.4. Fourth Stage: Comparison of the Fitting Methods

Comparison of the fitting regression methods in order to select the optimum technique for approximation function of ASR and determining factors affecting ASR were done on the basis of correlation coefficient (R), relative error indices, and using most powerful data mining software, IBM SPSS Modeler 14.2.

\section{Results}

Accident severity rate (ASR) of the occupational injuries was obtained as $557.47 \pm 397.87$ (Range: 136.0 to 2250.0).

Table 1 shows the descriptive results.

Table 1. Descriptive findings of the study

\begin{tabular}{|c|c|c|}
\hline \multicolumn{2}{|l|}{ Studied Factors } & Descriptive Values \\
\hline \multicolumn{2}{|l|}{ Age (years) $(\mathrm{M} \pm \mathrm{SD})$} & $27.82 \pm 5.23$ \\
\hline \multicolumn{2}{|l|}{ Work Experience $(\mathrm{M} \pm \mathrm{SD})$} & $4.39 \pm 3.65$ \\
\hline \multirow[t]{4}{*}{ Education } & Sub Diploma & $325(33.2 \%)$ \\
\hline & Diploma & $398(40.6 \%)$ \\
\hline & Upper diploma & $190(19.4 \%)$ \\
\hline & $\geq$ B.S & $67(6.8 \%)$ \\
\hline \multirow[t]{2}{*}{ Marital Status } & Single & $481(49.1 \%)$ \\
\hline & Married & $499(50.9 \%)$ \\
\hline \multirow[t]{3}{*}{ Job Title } & Simple Workers & $719(73.4 \%)$ \\
\hline & Technicians & $237(24.2 \%)$ \\
\hline & Supervisor & $24(2.4 \%)$ \\
\hline \multirow[t]{4}{*}{ Activity Type } & Normal Work & $641(65.4 \%)$ \\
\hline & Installation & $84(8.6 \%)$ \\
\hline & Maintenance & $172(17.6 \%)$ \\
\hline & Material Handling & $83(8.5 \%)$ \\
\hline \multicolumn{2}{|l|}{ Time Pressure } & $721(73.6 \%)$ \\
\hline \multicolumn{2}{|l|}{ Contractor } & $724(73.9 \%)$ \\
\hline \multirow[t]{7}{*}{ H\&S Training Factors (TF) } & Pre-employment training & $225(23.0 \%)$ \\
\hline & Periodic Training & $381(38.9 \%)$ \\
\hline & Past Injury Training & $135(13.8 \%)$ \\
\hline & PPE Training & $253(25.8 \%)$ \\
\hline & Housekeeping Training & $141(14.4 \%)$ \\
\hline & Quantity of Training & $258(26.3 \%)$ \\
\hline & Quality of Training & $245(25.0 \%)$ \\
\hline \multirow{9}{*}{$\begin{array}{l}\text { H\&S Risk Management Factors } \\
(\mathrm{RMF})\end{array}$} & HAZID & $182(18.6 \%)$ \\
\hline & Periodic risk assessment & $466(47.6 \%)$ \\
\hline & accident investigation & $167(17.0 \%)$ \\
\hline & Risk control measures; PPE & $272(27.8 \%)$ \\
\hline & TBM & $159(16.2 \%)$ \\
\hline & Housekeeping & $231(23.6 \%)$ \\
\hline & Checklist & $809(82.6 \%)$ \\
\hline & Incident Report & $128(13.1 \%)$ \\
\hline & H\&S Audit & $197(20.1 \%)$ \\
\hline
\end{tabular}


The descriptive findings of individual factors (IF) showed that the average age and work experience of injured workers were $27.82 \pm 5.23$ and $4.39 \pm 3.65$ years, respectively. The educational level of the workforce that was injured most frequently was diploma and sub-diploma level (73.8\%), and half of the injured workers were married $(50.9 \%)$. The results of organization factors (OF) showed that over $70 \%$ of injured workforces were simple workers and about $24.2 \%$ were technicians. Normal work had the high frequency of occupational injuries (67\%); and almost one-fifth of the injuries occurred in maintenance activities (17.6\%). In addition, the findings showed that time pressure was involved in $73.6 \%$ of occupational accidents and that $73.9 \%$ of occupational injuries happened to the contractor workforces. Analyzing the H\&S training process indicated that approximately one-fourth of the injured workforces $(23.0 \%)$ received pre-employment $\mathrm{H} \& \mathrm{~S}$ training, $39.9 \%$ participated in periodic training, and $13.8 \%$ received H\&S training after an injury occurred. Additionally, quality and quantity of trainings were estimated to be $25.0 \%$ and $26.3 \%$, respectively. The results of H\&S risk management factors showed that the proportion of main RMFs, including hazard identification (HAZID), periodic risk assessment, and accident investigation, were estimated to be $18.6 \%, 47.6 \%$, and $17.0 \%$, respectively. Furthermore, $\mathrm{H} \& \mathrm{~S}$ control measures that were implemented, including PPE, TBM, and housekeeping, were $27.8 \%, 16.2 \%$, and $23.6 \%$, respectively. Table 2 presents the results of using the four fitting methods, including linear regression, regression analysis, generalized linear model, and artificial neural networks (ANN), to analyze and model the factors that affected ASR. As it is shown, the factors, including age, quality of provided H\&S training, number of workers, HAZID, periodic risk assessment, and periodic H\&S training, were important factors that affected ASR. According to results of linear regression, regression analysis, and ANN, the average age was reckoned to be an important factor that affected ASR. The results of the generalized linear model showed that average work experience and quality of H\&S training were important factors that affected occupational injuries' severity.

Table 2. Analysis of health threatening factors by four fitting methods

\begin{tabular}{|l|l|l|l|l|}
\hline \multirow{2}{*}{ Factors } & \multicolumn{4}{|l}{ Importance value of each factors on ASR } \\
\cline { 2 - 5 } & $\begin{array}{l}\text { Linear } \\
\text { Regression }\end{array}$ & Regression & $\begin{array}{l}\text { Generalized } \\
\text { Linear Model }\end{array}$ & ANN \\
\hline Age & 0.14 & 0.16 & 0.09 & 0.20 \\
\hline Work Experience & 0.09 & 0.07 & 0.14 & 0.08 \\
\hline Education & 0.02 & 0.04 & 0.02 & 0.03 \\
\hline average of workers & 0.05 & 0.09 & 0.08 & 0.05 \\
\hline Activity Type & 0.07 & 0.06 & 0.02 & 0.04 \\
\hline Time Pressure & 0.02 & 0.02 & 0.01 & 0.03 \\
\hline Contractor & 0.01 & 0.02 & 0.01 & 0.02 \\
\hline Periodic Training & 0.08 & 0.09 & 0.04 & 0.05 \\
\hline Past Accident Training & 0.04 & 0.03 & 0.07 & 0.04 \\
\hline PPE Training & 0.03 & 0.02 & 0.01 & 0.02 \\
\hline Housekeeping Training & 0.01 & 0.02 & 0.01 & 0.02 \\
\hline Duration of Training & 0.03 & 0.04 & 0.08 & 0.06 \\
\hline Quality of Training & 0.10 & 0.06 & 0.14 & 0.10 \\
\hline HAZID & 0.09 & 0.10 & 0.09 & 0.07 \\
\hline Periodic risk assessment & 0.09 & 0.05 & 0.05 & 0.07 \\
\hline accident investigation & 0.08 & 0.04 & 0.06 & 0.06 \\
\hline PPE & 0.02 & 0.03 & 0.01 & 0.02 \\
\hline TBM & 0.01 & 0.02 & 0.02 & 0.01 \\
\hline Housekeeping & 0.01 & 0.02 & 0.01 & 0.02 \\
\hline H\&S Audit & 0.01 & 0.02 & 0.04 & 0.01 \\
\hline sum & 1.0 & 1.0 & 1.0 & 1.0 \\
\hline
\end{tabular}

The findings of the comparison of the four fitting methods in order to select the optimum technique for approximation function of ASR are shown in Figures 1-4. The results showed that the highest correlation coefficient (R) and the lowest relative error, respectively, were for the ANN model $(0.968,0.063)$, generalized linear model $(0.885,0.216)$, linear regression $(0.862,0.257)$, and regression analysis $(0.825,0.319)$. Therefore, the comparison of these fitting methods showed that ANN is the best fitting method to analyze and model the severity of occupational injuries. 


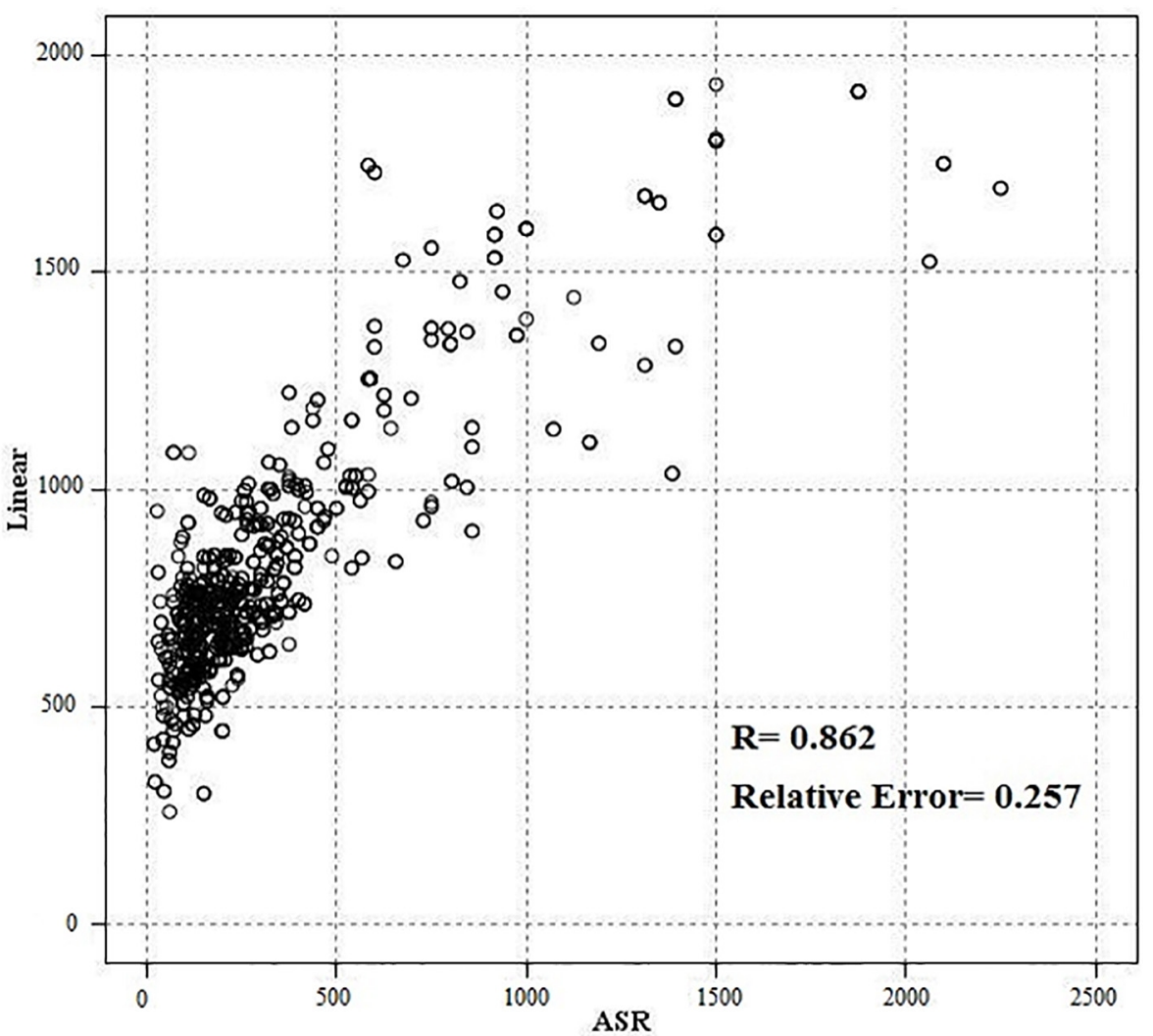

Figure 1. Regression between actual ASR and linear regression

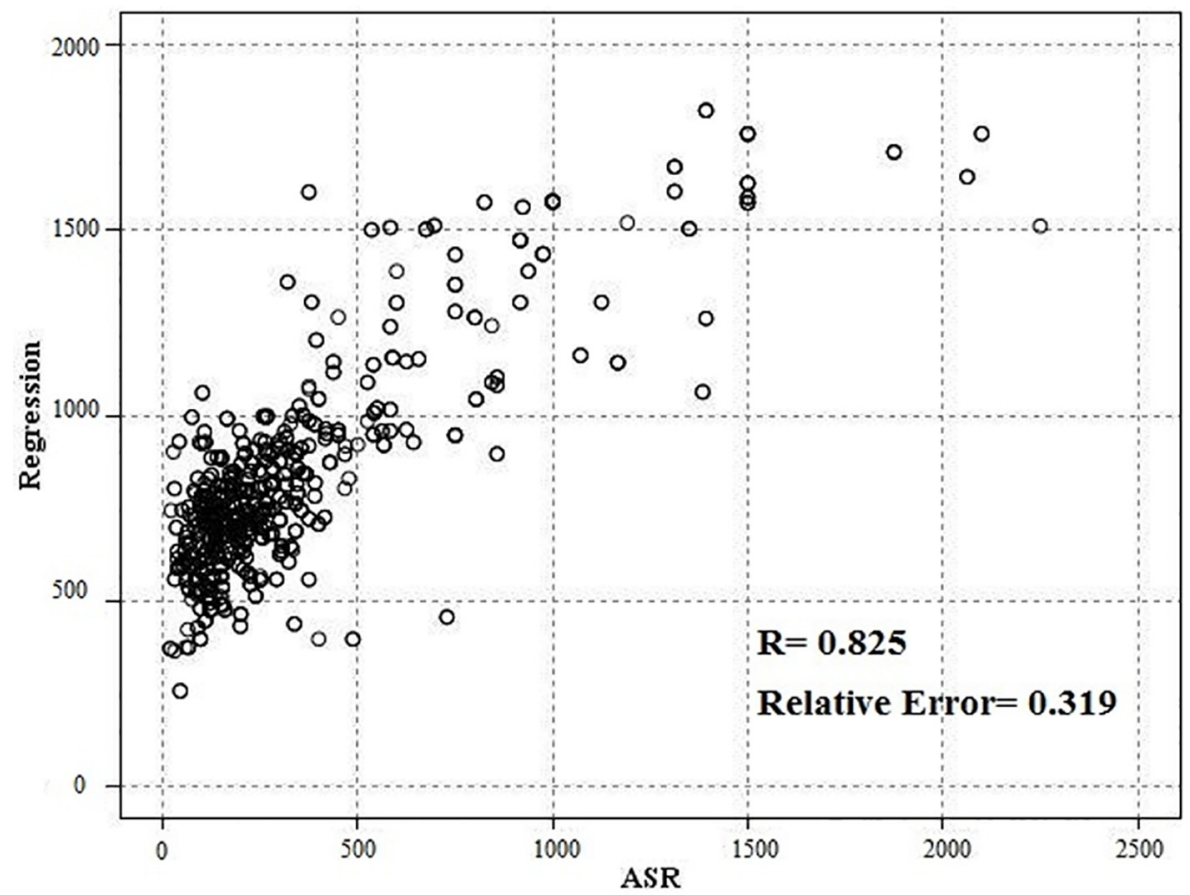

Figure 2. Regression between actual ASR and regression analysis 


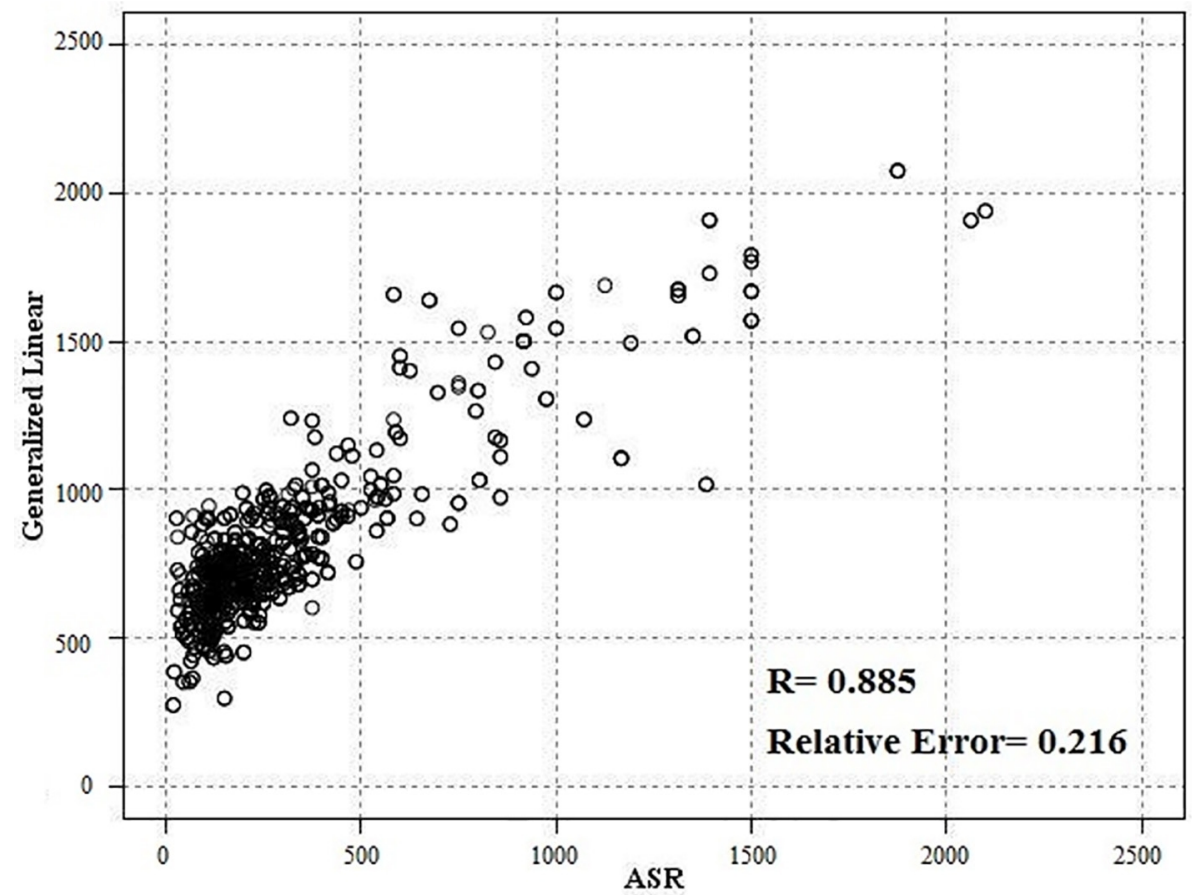

Figure 3. Regression between actual ASR and generalized linear model

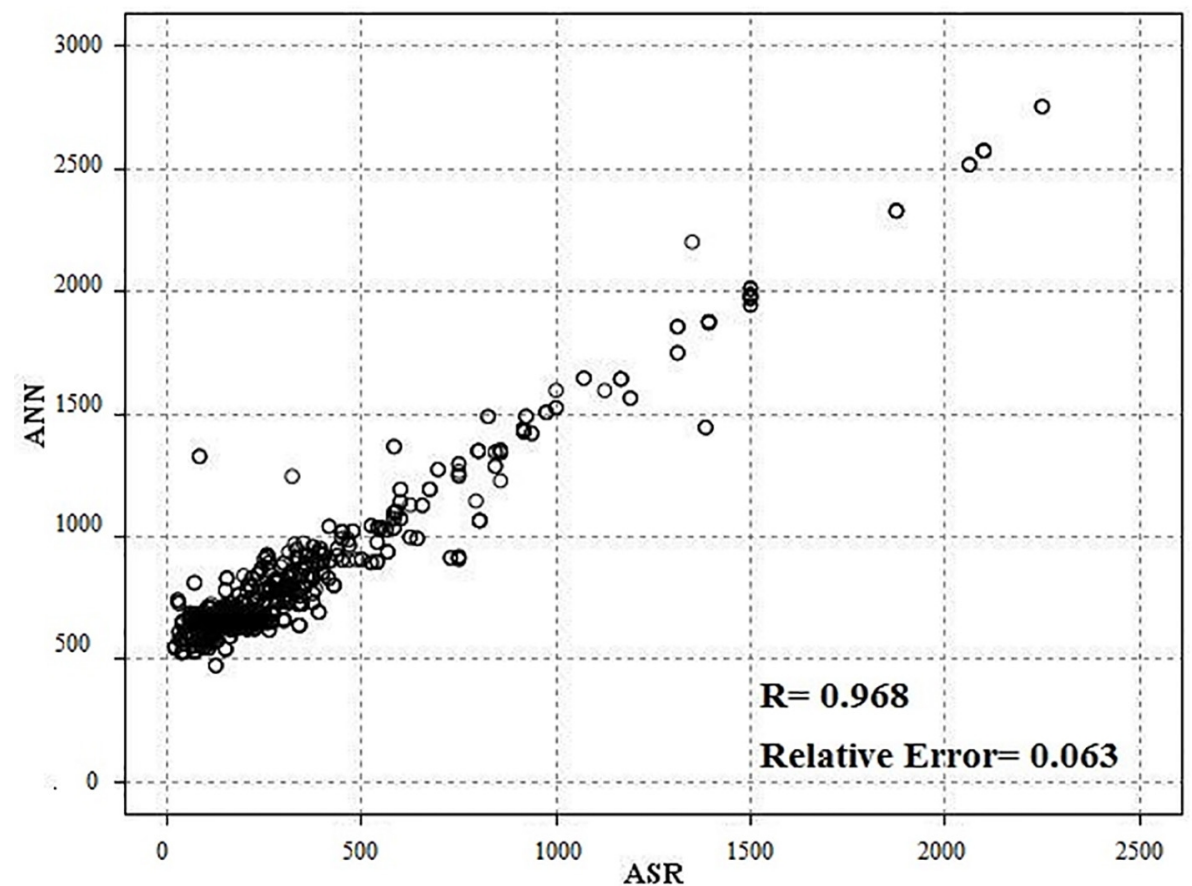

Figure 4. Regression between actual ASR and artificial neural networks (ANN)

\section{Discussion}

The findings of present study, which was designed and implemented based on using analytical fitting methods, indicated that occupational injuries, as one of the most important threats to workforce's health, are induced by several combinations of factors. These findings are consistent with results of other studies, and they indicated that individual factors (e.g., average age of workforce, work experience, and education level), organization factors (e.g., activity type, average number of workers in each activity, time pressure, and using contractor workforce), H\&S training factors (e.g., periodic and past injury training, PPE, housekeeping training, quality and quantity of training), 
H\&S risk management factors (e.g., HAZID, periodic risk assessment, accident investigation, using PPE, implementing TBM and housekeeping) as risk control measures and H\&S audit are the most important factors in causal analysis and modeling the severity of occupational injuries $(8,23-25)$. Consistent with the findings of the study, other studies have reported that individual and organizational factors can play a significant role in the incidence and severity of occupational injuries $(24,26)$. Haslam et al. revealed that workers play a direct role in $70 \%$ of the injuries caused by human error and unsafe acts (26). The importance of individual factors on the grounds that workers are responsible for the protection of their lives proved the effects of these factors on each type of job and activity that is involved $(24,26-28)$. According to the findings, organization factors are the most important factors of occupational injuries. Organizational factors have two roles and impacts on the severity of occupational injuries. Factors such as the type of activity can directly affect the severity of injuries. In addition, the number of workers and time pressure as a mediator can affect the severity of injuries $(10,26)$. Studies have reported that awareness and readiness to workplace hazards is one way to prevent and reduce the severity of occupational injuries, thus the H\&S training factor is the most important factor of the injuries' severity $(23,25)$. Lack and inadequacy of training and a poor health and safety climate have been shown to be the root causes of occupational injuries that have an impact on workforces' health $(27,29)$. Also, the results of four fitting methods indicated that H\&S training factors significantly affected ASR and defects in the design and implementation of appropriate H\&S training programs, which can cause serious and sometimes tragic health effects $(23,25,27,29)$. Furthermore, consistent with other studies, the findings revealed that poor design and implementation of factors associated with H\&S risk management, including the establishment of a hazard identification system (HAZID), periodic risk assessment, developing and implementing accident investigations, and risk control measures, such as PPE, implementing TBM, and housekeeping, can play a significant and determinative role in severe health threats of occupational injuries $(24-25,30)$.

It was observed that the fitting analysis techniques seemed practical and applicable to analyze and model the health threats and the factors affecting them. Therefore, based on the more significant and strong findings, all of the fitting analysis methods can be used in setting goals and policies and to design health programs to prevent and reduce the severity of occupational injuries in large-scale workplaces. Furthermore, the comparison of the findings of the four fitting methods revealed that, despite the suitability and applicability of all of the methods, ANN had the best correlation coefficient (R) and the lowest relative error, so this fitting method can be selected as the optimum technique for approximating the severity of occupational injuries and other health consequences in large-scale workplaces. Some studies also have suggested that ANN as a good technique to analyze and model health and safety threatening factors to workforces $(15,31,32)$. For example, Carrillo-Castillo and co-workers applied ANN to model and predict accidents' severity in the manufacturing sector, and they confirmed that neural networks were useful in estimating accident's risk factors (31). Also, Moghaddam et al. used artificial neural networks to predict the severity of highway crashes and showed that the best application of ANN was in estimating the severity of injuries (32). It seems that a comprehensive study should be designed and implemented in the future with the purpose of analyzing and modeling health effects, such as occupational injuries using the ANN technique.

Finally, the limitations of this study included the high time consumption of data gathering; in addition, the geographical distribution of the studied workplaces was high. In addition, the main limitations to generalizing the results to the larger populations were providing the introduced fitting methods as a common method for analysis and modeling of occupational injuries, as well as training H\&S engineers how to use these analytical techniques.

\section{Conclusions}

The results affirmed that all of the fitting methods were suitable and applicable in analyzing and modeling the severity of occupational injuries. Furthermore, comparison of the fitting methods revealed that ANN was the best analytical modeling approach in the analysis of occupational injuries in large-scale workplaces. Therefore, all fitting methods, especially ANN, should be considered more in analyzing and modeling of occupational injuries and health-threatening factors as well as planning to provide and improve workforce's health. Also, it seems that a comprehensive study aimed at analyzing and modeling of occupational injuries and other health and safety issues using the ANN technique should be designed and implemented in the future.

\section{Acknowledgments:}

This paper was extracted from the $\mathrm{PhD}$ thesis in Occupational Health Engineering of the corresponding author. We acknowledge the Research Center for Health Sciences at Hamadan University of Medical Sciences, for partially funding this research. The authors wish to sincerely thank HSE engineers of the 10 large construction workplaces 
and Mr. Shahram Mahmudi for their invaluable and skillful assistance in data gathering in the studied large-scale workplaces and industries.

\section{Conflict of Interest:}

There is no conflict of interest to be declared.

\section{Authors' contributions:}

All authors contributed to this project and article equally. All authors read and approved the final manuscript.

\section{References}

1) Tint P, Paas Õ, Reinhold K. Cost-Effectiveness of Safety Measures in Enterprises. Engineering Economics. 2015;21(5).

2) Gholipour C, Vahdati SS, Ghaffarzade E, Zonouzi KK. Characteristics of Fatal Occupational Traumatic Injuries; Drama in East Azerbaijan Province of Iran. Bulletin of Emergency And Trauma. 2015;3(1 JAN):27-31.

3) Alizadeh SS. Estimation of economic costs of accidents at work in Iran: A case study of occupational accidents in 2012. Iran Occupational Health. 2015;12(1):12-9.

4) Mehrdad R, Seifmanesh S, Chavoshi F, Aminian O, Izadi N. Epidemiology of occupational accidents in Iran based on social security organization database. Iranian Red Crescent Medical Journal. 2014;16(1). DOI: 10.5812/ircmj.10359, PMid: 24719699, PMCid: PMC3964417

5) Fernández-Muñiz B, Montes-Peón JM, Vázquez-Ordás CJ. Relation between occupational safety management and firm performance. Safety science. 2009;47(7):980-91. DOI: 10.1016/j.ssci.2008.10.022

6) Hämäläinen P, Takala J, Saarela KL. Global estimates of occupational accidents. Safety science. 2006;44(2):137-56. DOI: 10.1016/j.ssci.2005.08.017

7) Fernández-Muñiz B, Montes-Peón JM, Vázquez-Ordás CJ. Safety management system: Development and validation of a multidimensional scale. Journal of Loss Prevention in the process Industries. 2007;20(1):5268. DOI: $10.1016 /$ j.jlp.2006.10.002

8) Amini SM, Gilaki M, Karchani M. Safety of Nanotechnology in Food Industries. Electronic physician. 2014;6(4):962.

9) Teymuri GH, Sadeghian M, Kangavari M, Asghari M, Madrese E, Abbasinia M, et al. Review the number of accidents in Tehran over a two-year period and prediction of the number of events based on a time-series model. Electronic physician. 2013;5.

10) Mearns K, Rundmo T, Flin R, Gordon R, Fleming M. Evaluation of psychosocial and organizational factors in offshore safety: a comparative study. Journal of Risk Research. 2004;7(5):545-61. DOI: $10.1080 / 1366987042000146193$

11) Teo EA-L, Feng Y. The indirect effect of safety investment on safety performance for building projects. Architectural Science Review. 2011;54(1):65-80. DOI: 10.3763/asre.2009.0090

12) Sari M, Selcuk AS, Karpuz C, Duzgun HSB. Stochastic modeling of accident risks associated with an underground coal mine in Turkey. Safety science. 2009;47(1):78-87. DOI: 10.1016/j.ssci.2007.12.004

13) Cowlagi RV, Saleh JH. Coordinability and consistency in accident causation and prevention: formal system theoretic concepts for safety in multilevel systems. Risk analysis. 2013;33(3):420-33. DOI: 10.1111/j.15396924.2012.01886.x, PMid: 22967134

14) Mahmoodabab SSM, Mohammadi M, Abad MAMS. Application of Transtheoretical Model to Exercise in Office Staff. Electronic physician. 2013;5.

15) Khelassi A. Explanation-aware computing of the prognosis for breast cancer supported by IK-DCBRC: Technical innovation. Electronic physician. 2014;6(4):947.

16) $\mathrm{Wu} \mathrm{S}$, Li H, Zhu W, Li J, Wang X. A structural equation model relating work stress, coping resource, and quality of life among chinese medical professionals. American Journal of Industrial Medicine. 2010;53(11):1170-6. DOI: 10.1002/ajim.20864, PMid: 20957728

17) Chinda T, Mohamed S. Structural equation model of construction safety culture. Engineering, Construction and Architectural Management. 2008;15(2):114-31. DOI: 10.1108/09699980810852655

18) OSHA. Safety \& health managment system etool. 2012; available from: http://www.osha.gov/SLTC/etools/safetyhealth/mod1_estimating_costs.html

19) Ahmadi M, Moosazadeh M, Vardanjani HM-e, Dehghan A. Prevalence of obesity and overweight and their related factors among the adults of Mazandaran Province, Iran, in 2010. Electronic physician. 2014;6(4):955. 
20) Priyadarshini E, Babu AC. A Comparative Analysis for forecasting the NAV's of Indian Mutual Fund using Multiple Regression Analysis and Artificial Neural Networks. International Journal of Trade Economics. 2011;3(5).

21) Fahrmeir L, Tutz G. Multivariate statistical modelling based on generalized linear models: Springer Science \& Business Media; 2013.

22) Kirkland K. Computer Science: Notable Research and Discoveries: Infobase Publishing; 2010.

23) Kalte HO, Hosseini AH, Arabzadeh S, Najafi H, Dehghan N, Akbarzadeh A, et al. Analysis of electrical accidents and the related causes involving citizens who are served by the Western of Tehran. Electronic physician. 2014;6(2):820.

24) Rahmani A, Mahmodkhani S, Moslemi M, Gharagozlou F, Ahmadnezhad I, Karchani M, et al. Investigation of Occupational Stress and its Relationship with the Demographic Characteristics of Workers in Ilam, Iran. Electronic physician. 2013;5.

25) Kalte HO, Ziaei M, Najafi H, Karami A, Akbarzadeh A, Ahmadnezhad I, et al. Use of the Finnish method to quantify the ergonomic properties in an office environment among the workplaces in an Electricity Distribution Company in West Tehran Province. Electronic physician. 2014;6(1):779.

26) Haslam R, Hide S, Gibb AG, Gyi DE, Pavitt T, Atkinson S, et al. Contributing factors in construction accidents. Applied Ergonomics. 2005;36(4):401-15. DOI: 10.1016/j.apergo.2004.12.002, PMid: 15892935

27) Pinto A, Nunes IL, Ribeiro RA. Occupational risk assessment in construction industry-Overview and reflection. Safety science. 2011;49(5):616-24. DOI: 10.1016/j.ssci.2011.01.003

28) Cheng C-W, Leu S-S, Cheng Y-M, Wu T-C, Lin C-C. Applying data mining techniques to explore factors contributing to occupational injuries in Taiwan's construction industry. Accident Analysis \& Prevention. 2012;48:214-22. DOI: 10.1016/j.aap.2011.04.014, PMid: 22664684

29) Gervais M. Good management practice as a means of preventing back disorders in the construction sector. Safety science. 2003;41(1):77-88. DOI: 10.1016/S0925-7535(01)00070-4

30) Väyrynen S, Häkkinen K, Niskanen T. Integrated Occupational Safety and Health Management: Solutions and Industrial Cases: Springer; 2015. DOI: 10.1007/978-3-319-13180-1

31) Carrillo-Castrillo JA, Martín JG, de la Vega RG, Onieva L. Neural Network Application for Risk Factors Estimation in Manufacturing Accidents. Managing Complexity: Springer; 2014. p. 277-83.

32) Moghaddam FR, Afandizadeh S, Ziyadi M. Prediction of accident severity using artificial neural networks. International Journal of Civil Engineering. 2011;9(1):41. 